\title{
Field Attractants for Pachnoda interrupta Selected by Means of GC-EAD and Single Sensillum Screening
}

\author{
Jonas M. Bengtsson • Yitbarek Wolde-Hawariat • Hamida Khbaish • Merid Negash • \\ Bekele Jembere • Emiru Seyoum • Bill S. Hansson • Mattias C. Larsson • Ylva Hillbur
}

Received: 16 March 2009 /Revised: 30 July 2009 / Accepted: 18 August 2009 /Published online: 11 September 2009

(C) Springer Science + Business Media, LLC 2009

\begin{abstract}
The sorghum chafer, Pachnoda interrupta Olivier (Coleoptera: Scarabaeidae: Cetoniinae), is a key pest on sorghum, Sorghum bicolor (L.) Moench (Poaceae), in Ethiopia. At present there is a lack of efficient control methods. Trapping shows promise for reduction of the pest population, but would benefit from the development of attractive lures. To find attractants that could be used for control of $P$. interrupta, either by mass trapping or by monitoring as part of integrated pest management, we screened headspace collections of sorghum and the highly attractive weed Abutilon figarianum Webb (Malvaceae) for antennal activity using gas chromatograph-coupled electroantennographic detection (GC-EAD). Compounds active in GC-EAD were identified by combined gas chromatography and mass spectrometry (GC-MS). Field trapping suggested that attraction is governed by a few influential compounds,
\end{abstract}

Dr. Bekele Jembere passed away on March 26th 2009 due to sudden illness. We dedicate this article to his memory.

J. M. Bengtsson $(\triangle) \cdot$ Y. Wolde-Hawariat $\cdot H$. Khbaish •

B. S. Hansson - M. C. Larsson · Y. Hillbur

Department of Plant Protection Biology,

Swedish University of Agricultural Sciences,

PO Box 44, 230 53, Alnarp, Sweden

e-mail: Jonas.Bengtsson@1tj.slu.se

Y. Wolde-Hawariat · M. Negash • B. Jembere · E. Seyoum

Department of Biology, Addis Ababa University,

PO Box 1176, Addis Ababa, Ethiopia

Y. Wolde-Hawariat

Department of Plant Sciences, Wollo University,

Dessie, Ethiopia

M. Negash · B. S. Hansson

Department of Evolutionary Neuroethology,

Max Planck Institute for Chemical Ecology,

Hans-Knoell-Strasse 8,

Jena, Germany rather than specific odor blends. Synthetic sorghum and abutilon odor blends were attractive, but neither blend outperformed the previously tested attractants eugenol and methyl salicylate, of which the latter also was part of the abutilon blend. The strong influence of single compounds led us to search for novel attractive compounds, and to investigate the role of individual olfactory receptor neurons (ORNs) in the perception of kairomones. We screened the response characteristics of ORNs to 82 putative kairomones in single sensillum recordings (SSR), and found a number of key ligand candidates for specific classes of ORNs. Out of these key ligand candidates, six previously untested compounds were selected for field trapping trials: anethole, benzaldehyde, racemic 2,3-butanediol, isoamyl alcohol, methyl benzoate and methyl octanoate. The compounds were selected on the basis that they activated different classes of ORNs, thus allowing us to test potential kairomones that activate large non-overlapping populations of the peripheral olfactory system, while avoiding redundant multiple activations of the same ORN type. Field trapping results revealed that racemic 2,3-butanediol is a powerful novel attractant for P. interrupta.

Keywords Electrophysiology · Field trapping test . Olfaction · Polyphagous herbivore - Pest control · Attractants $\cdot$ Pachnoda interrupta $\cdot$ Sorghum chafer . Coleoptera $\cdot$ Scarabaeidae

\section{Introduction}

The adult sorghum chafer, Pachnoda interrupta, is a polyphagous herbivore that feeds on fruits and flowers of several plant species, e.g., banana (Musa spp.), mango (Mangifera spp.), acacia (Acacia spp.), orange (Citrus sinensis), and papaya (Carica papaya) (Clark and Crowe 
1978; Hiwot 2000). Fermentation products, e.g., residue (dregs) from tella, an Ethiopian beer-like beverage, are highly attractive to the beetles (Ministry of Agriculture and Ethiopian Agricultural Research Organization 1999). Tella is a spontaneously fermented beer (no yeast is added) that is brewed using water, flour of sorghum or other cereals, malt of barley or wheat, with crushed leaves of shiny-leaf buckthorn, Rhamnus prinoides Eschsch. (Rhamnaceae), instead of hops. Pachnoda interrupta adults also feed on the herbaceous weed abutilon, Abutilon figarianum, and food crops such as pearl millet, Pennisetum glaucum and sorghum, Sorghum bicolor (Schmutterer 1969; Grunshaw 1992; Jago 1995; Sastawa and Lale 2000). During the early 1990s, the sorghum chafer emerged as a key pest on sorghum in Ethiopia (Hiwot 2000). Mean percent loss of sorghum yield due to $P$. interrupta infestation can be as high as $70 \%$ (Yitbarek and Hiwot 2000). Efficient control methods for this pest insect are lacking, but trapping by using fruit (mainly Musa spp.) as bait shows promise for decreasing the pest population (Ministry of Agriculture and Ethiopian Agricultural Research Organization 1999). The efficiency of trapping could be improved by using better traps and synthetic, standardized attractants (Wolde-Hawariat et al. 2007). Previous field experiments indicate that compounds commonly found in the odor profile of flowers and fruits have potential as attractants for P. interrupta, with high levels of attraction especially to methyl salicylate and eugenol (Wolde-Hawariat et al. 2007). Single compounds are efficient lures for many scarab species that feed on fruits and flowers (Donaldson et al. 1990), and studies have shown a high degree of overlap between active compounds identified from different food sources (Stensmyr et al. 2001). Continued efforts in field testing of novel synthetic attractants for the Japanese beetle, Popillia japonica, have led to the development of lures far outperforming initial versions (Potter and Held 2002).

In search of attractants for pest insects, various approaches have been employed. Trial-and-error field screening of compounds has led to the identification of powerful attractants, e.g., for P. japonica (Potter and Held 2002). A commonly employed method in search of field attractants is gas chromatography with electroantennographic detection (GC-EAD; Arn et al. 1975), which allows the identification of antennally active compounds in the volatile blends emitted by hosts. GC-EAD has led to the identification of several powerful kairomonal field attractants (see e.g., Linn et al. 2005). Few studies, however, have employed single sensillum recordings (SSR) to identify behaviorally active compounds (Stensmyr et al. 2001; Larsson et al. 2002, 2003; Ulland et al. 2008), even though SSR may be a highly sensitive tool in detecting physiologically active components in the volatile profiles of host plants (Wibe 2004), including compounds that do not elicit detectable GC-EAD responses
(Blight et al. 1995; Wu et al. 1995; Barata et al. 2002). SSR usually has been employed as a means of describing and understanding the sense of olfaction, specifically the olfactory receptor populations of antennae and palps (see e.g., Larsson et al. 2001; Mustaparta 2002).

We employed GC-EAD on volatile collections from sorghum and abutilon to identify compounds responsible for attraction of $P$. interrupta to these plants in the field. We also screened olfactory receptor neurons (ORNs) on the sorghum chafer antenna with potential kairomones using SSR. The behavioral activity of several compounds active in GC-EAD and SSR was tested in field trials, in search of potent attractants. Such attractants could be used in future control efforts, either in mass trapping or in monitoring, or as part of integrated pest management.

\section{Methods and Materials}

Insects for Electrophysiological Experiments Male and female sorghum chafers were collected at Rasa $\left(09^{\circ} 55^{\prime} \mathrm{N}\right.$, $40^{\circ} 05^{\prime} \mathrm{E}$ ), located $255 \mathrm{~km}$ northeast of Addis Ababa, Ethiopia. Adult beetles were sexed based on the presence of a ventral, abdominal groove in males (Rigout 1989), and kept separately. After transport to Alnarp, Sweden, adults were kept in clear plastic boxes $(30 \times 12 \times 22 \mathrm{~cm}$, Cofa Plastics AB, Stockholm, Sweden) with a 1:1:1 mixture of planting soil (Yrkesplantjord, Weibull Trädgård $A B$, Hammenhög, Sweden), peat (Växa trädgårdstorv, Econova Garden AB, Åse, Sweden) and composted cow dung (Simontorps Bas, Weibull Trädgård AB). Boxes were kept at $25^{\circ} \mathrm{C}, 70 \%$ relative humidity, and a $\mathrm{L} 16$ :D8 $\mathrm{h}$ cycle. The beetles were fed with apples and bananas ad libitum.

Headspace Plant Volatile Collection Volatiles were collected from the developmental stage of the plant most attractive to the beetles, during the time of day when the beetles feed intensively, i.e., $10 \mathrm{am}$ to $4 \mathrm{pm}$. For abutilon, the top $20 \mathrm{~cm}$ of a single abutilon plant, including flowers, seed pods, and leaves, was enclosed for each collection. For sorghum, volatiles were collected from a single panicle at the soft dough stage (milky stage). Polyacetate bags $(35 \times 43 \mathrm{~cm}$; Toppits Scandinavia AB, Sweden) sealed with steel wire around the stem of the plant were used for aerations. An activated charcoal filter was placed next to the stem to filter incoming air. Volatiles were collected on glass tube columns ( $3.5 \mathrm{~mm}$ i.d. $\times$ $50 \mathrm{~mm}$ ) packed with $25 \mathrm{mg}$ SuperQ ${ }^{\circledR}$, mesh 80/100 (Alltech, Deerfield, IL, USA) with glass wool and Teflon stoppers at both ends (Birgersson and Bergström, 1989). The filter was placed in the polyacetate bag and connected by PVC tubing to a small battery operated pump (PAS-500 Personal Air Sampler, Supelco, Bellefonte, PA, USA). The flow of the pump was $200 \mathrm{ml} / \mathrm{min}$, and collections were made in the field 
for $2 \mathrm{~h}$. Immediately after collection, the columns were rinsed with $200 \mu 1$ of redistilled hexane into $1.1 \mathrm{ml}$ tapered glass vials (1.1 STVG, Chromacol Ltd., Welwyn Garden City, UK). Vials with extracts were kept in an icebox for transportation to the laboratory, and thereafter kept at $-18^{\circ} \mathrm{C}$ until analysis.

Gas Chromatograph-Coupled Electroantennographic Detection (GC-EAD) The response of $P$. interrupta antennae to volatiles was studied by GC-EAD using an Agilent Technologies gas chromatograph (GC), model 6890, equipped with a fused silica capillary column $(30 \mathrm{~m} \times 0.2 \mathrm{~mm})$ coated with Innowax $(0.25 \mu \mathrm{m}$ film thickness) (Agilent Technologies Inc., Santa Clara, CA, USA). For each run, $2 \mu 1$ of sample were injected in splitless mode. Hydrogen was used as mobile phase at a linear velocity of $45 \mathrm{~cm} / \mathrm{sec}$. The oven temperature was programmed from $40^{\circ} \mathrm{C}$ ( 5 min hold) to $230^{\circ} \mathrm{C}$ at $5^{\circ} \mathrm{C} / \mathrm{min}$. Compounds eluting from the column were split 1:1 in a four-way splitter, with nitrogen as make up gas $(20 \mathrm{ml} / \mathrm{min})$, and delivered to the FID and to the antenna. Compounds were carried to the antenna through a glass tube by a charcoal-filtered and humidified air stream at $0.5 \mathrm{~m} / \mathrm{sec}$. Antennae were mounted according to Leal et al. (1992) and Wolde-Hawariat et al. (2007). The antenna was excised with fine forceps and placed in an antennal holder (Hillbur 2001; JoAC, Lund, Sweden), and the signal was amplified (JoAC) and analyzed with GC-EAD software (Syntech, Hilversum, The Netherlands). EAD responses to FID peaks were defined as repeatable deflections of the baseline. Each extract was tested on five different antennae per sex, for a total of ten antennae per extract.

Chemical Identification Samples of plant volatile collections were analyzed by combined gas chromatography and mass spectrometry (GC-MS) Hewlett Packard 6890 GC and 5973 MS (Agilent Technologies Inc.). Extracts were injected with an HP 7683 auto injector in splitless mode. The GC was fitted with the same column under the same conditions as for GC-EAD, but usinig helium $(35 \mathrm{~cm} / \mathrm{sec})$ as carrier. Peaks were matched between GC-EAD and GC-MS by retention index. Identifications of compounds were confirmed by comparison of mass spectra in the NIST 1998 and Wiley 1998 commercial mass spectral databases, and with those of authentic GC standards, except for methyl anthranilate, which was not available at the time when GC-MS analysis was done.

Synthetic Compounds Synthetic standards for all experiments were purchased from Sigma-Aldrich (for purity and CAS number, see Table 1). A total of 82 compounds were used in single sensillum recordings (Table 1). The compounds include volatiles commonly found in flowers (Knudsen et al. 2006), volatiles from tropical fruit (Macku and Jennings 1987; Ibáñes et al. 1998; Boudhrioua et al. 2003; Carasek and Pawliszyn 2006; Clara et al. 2007;
Pandit et al. 2009), and volatiles related to microbial degradation and fermentation (Chatonnet et al. 1992; Fischer et al. 2000; Xiao and Ping 2007). Approximately half of the compounds used previously have been found to elicit behavioral or electrophysiological activity in the sorghum chafer or related scarab beetles (Stensmyr et al. 2001; Larsson et al. 2003; Wolde-Hawariat et al. 2007).

Single Sensillum Recordings (SSR) Single synthetic compounds were diluted to $1 \mu \mathrm{g} / \mu \mathrm{l}$ in acetone or hexane, depending on polarity (Table 1). Highly volatile compounds were diluted to $1 \mu \mathrm{g} / \mu \mathrm{l}$ in paraffin oil. Blends of $2-10$ compounds, with each component at the same concentration as in the single compound dilutions, were also prepared for screening purposes (see below; Table 1). Stimuli were prepared by applying $10 \mu \mathrm{l}$ of $1 \mu \mathrm{g} / \mu \mathrm{l}$ solution to a $1.5 \times$ $1 \mathrm{~cm}$ piece of Whatman filter paper (No. 3, Whatman, Maidstone, United Kingdom) that was placed in a disposable Pasteur pipette (150 mm soda lime glass, VWR International, Stockholm, Sweden). For compounds diluted in hexane or acetone, solvent was allowed to evaporate before stimuli were used in experiments. After evaporation of solvent, $1 \mathrm{ml}$ pipette tips were put on the wide end of the Pasteur pipettes, to reduce any further evaporation of the test compound(s). Between trials, stimulus pipettes were kept at $-18^{\circ} \mathrm{C}$, to avoid evaporation. For comparison, stimulus pipettes containing only solvent as well as empty pipettes were prepared. To ensure that stimulus pipettes were not exhausted, new ones were prepared once per week (after having been used a maximum of ten times), except for screening pipettes, where new ones were prepared each day.

Insects were restrained with Parafilm (PM-992, Pecheney plastic packaging, Menasha, WI, USA) and fixed on microscope slides (ca. $76 \times 26 \mathrm{~mm}$, Menzel-Gläser, Braunschweig, Germany) using dental wax (Surgident periphery wax, Heraeus Kulzer GmbH, Hanau, Germany), with the lamellae held open on a wax surface using 2-3 mm long pieces of thin tungsten wire. A silver grounding electrode was inserted into the abdomen. Sensilla were contacted with a tungsten electrode (diam $0.12 \mathrm{~mm}$, Harvard Apparatus Ltd, Edenbridge, United Kingdom) electrolytically sharpened in a saturated $\mathrm{KNO}_{2}$ solution (Hubel 1957), using a DC-3K Rechts PM-10 piezo micromanipulator (Märzhäuser Wetzler $\mathrm{GmbH}$, Wetzler, Germany). The signal from the ORNs was registered and amplified 10 times with a probe (INR-02, Syntech), amplified 200 times with a Syntech UN-06 AC/ DC amplifier, and transferred to a computer through an IDAC-4-USB (Syntech), where it was visualized and analyzed with the software Autospike v. 2.2 (Syntech).

A constant flow of $0.5 \mathrm{~m} / \mathrm{sec}$ of charcoal-filtered and humidified air was delivered through a glass tube with its outlet approximately $15 \mathrm{~mm}$ from the antenna. Stimuli were presented to the insect by inserting the stimulus pipette 
Table 1 Synthetic compounds used for single cell screening

\begin{tabular}{|c|c|c|c|c|}
\hline$\#$ & Compound & $\mathbf{S}$ & CAS & $\%$ \\
\hline$* 1$ & 4-Ethylphenol & $\mathrm{A}$ & $123-07-9$ & 99 \\
\hline$* 1$ & 4-Methylphenol & $\mathrm{A}$ & $106-44-5$ & 99 \\
\hline$* 2$ & (E)-2-Hexenal & $\mathrm{H}$ & $6728-26-3$ & 98 \\
\hline$* 2$ & (E)-2-Hexen-1-ol & $\mathrm{H}$ & $928-95-0$ & 96 \\
\hline *2 & (E)-2-Hexenyl acetate & $\mathrm{H}$ & $2497-18-9$ & 98 \\
\hline$* 2$ & (E)-3-Hexen-1-ol & $\mathrm{H}$ & $928-97-2$ & 98 \\
\hline *2 & (Z)-3-Hexen-1-ol & $\mathrm{H}$ & $928-96-1$ & 98 \\
\hline$* 2$ & (Z)-3-Hexenyl acetate & $\mathrm{H}$ & $3681-71-8$ & 98 \\
\hline 3 & Hexanal & $\mathrm{H}$ & $66-25-1$ & 98 \\
\hline$* 3$ & 1-Hexanol & $\mathrm{H}$ & $111-27-3$ & 98 \\
\hline *3 & Hexyl acetate & $\mathrm{H}$ & $142-92-7$ & 98 \\
\hline$* 3$ & Nonanal & $\mathrm{H}$ & $124-19-6$ & 95 \\
\hline 3 & 1-Nonanol & $\mathrm{H}$ & $143-08-8$ & 99,5 \\
\hline *3 & 1-Octanol & $\mathrm{H}$ & $111-87-5$ & 99,5 \\
\hline$* 3$ & $( \pm)$-3-Octanol & $\mathrm{H}$ & $589-98-0$ & 99 \\
\hline$* 3$ & $( \pm)$-1-Octen-3-ol & $\mathrm{H}$ & $3391-86-4$ & 98 \\
\hline$* 4$ & Anethole & $\mathrm{H}$ & $4180-23-8$ & 99 \\
\hline$* 4$ & Benzaldehyde & $\mathrm{H}$ & $100-52-7$ & 99,5 \\
\hline$* 4$ & Benzylalcohol & $\mathrm{H}$ & $100-51-6$ & 99 \\
\hline$* 4$ & Eugenol & $\mathrm{H}$ & $97-53-0$ & 98 \\
\hline$* 4$ & Methyl benzoate & $\mathrm{H}$ & $93-58-3$ & 99 \\
\hline 4 & Methyl anthranilate & $\mathrm{H}$ & $134-20-3$ & 99 \\
\hline$* 4$ & 2-Phenylethanol & $\mathrm{H}$ & $60-12-8$ & 98 \\
\hline$* 4$ & 2-Phenylethyl propionate & $\mathrm{H}$ & $122-70-3$ & 98 \\
\hline *5 & $( \pm)$-Acetoin & $\mathrm{A}$ & $513-86-0$ & 97 \\
\hline *5 & racemic 2,3-Butanediol & $\mathrm{A}$ & $513-85-9$ & 99 \\
\hline 5 & Carvacrol & A & $499-75-2$ & 98 \\
\hline 5 & Cinnamic aldehyde & A & $104-55-2$ & 98 \\
\hline$* 5$ & Methyl cinnamate & A & $103-26-4$ & 99 \\
\hline *5 & Methyl salicylate & A & $119-36-8$ & 99 \\
\hline$* 5$ & Phenylacetaldehyde & A & $122-78-1$ & 90 \\
\hline$* 5$ & Phenylacetonitrile & A & $140-29-4$ & 99 \\
\hline$* 5$ & Thymol & A & $89-83-8$ & 99,5 \\
\hline *6 & Butyric acid & $\mathrm{H}$ & $107-92-6$ & 99 \\
\hline *6 & N-Caproic acid & $\mathrm{H}$ & $142-62-1$ & 99,5 \\
\hline *6 & Isovaleric acid & $\mathrm{H}$ & $503-74-2$ & 98 \\
\hline 6 & Valeric acid & $\mathrm{H}$ & $109-52-4$ & 99,8 \\
\hline$* 7$ & Isoamyl alcohol & $\mathrm{H}$ & $123-51-3$ & 98 \\
\hline$* 7$ & 6-Methyl-5-hepten-2-one & $\mathrm{H}$ & $78-70-6$ & 99 \\
\hline 7 & Tetradecane & $\mathrm{H}$ & $629-59-4$ & 99,5 \\
\hline 7 & Tridecane & $\mathrm{H}$ & $629-50-5$ & 99,5 \\
\hline *8 & $( \pm)$-beta-Caryophyllene & $\mathrm{H}$ & $87-44-5$ & 98,5 \\
\hline$* 8$ & (-)-trans-Citronellol & $\mathrm{H}$ & $106-22-9$ & 95 \\
\hline *8 & Geraniol & $\mathrm{H}$ & $106-24-1$ & 98 \\
\hline$* 8$ & Geranyl acetate & $\mathrm{H}$ & $105-87-3$ & 98 \\
\hline$* 8$ & $( \pm)$-Linalool & $\mathrm{H}$ & $78-70-6$ & 97 \\
\hline$* 8$ & Linalool oxides & $\mathrm{H}$ & $\mathrm{n} / \mathrm{a}$ & 97 \\
\hline 8 & Methyl jasmonate & $\mathrm{H}$ & $1211-29-6$ & 95 \\
\hline 8 & Nerolidol & $\mathrm{H}$ & $7212-44-4$ & 98 \\
\hline
\end{tabular}

Table 1 (continued)

\begin{tabular}{|c|c|c|c|c|}
\hline \# & Compound & $\mathbf{S}$ & CAS & $\%$ \\
\hline 9 & $( \pm)$-delta-Decalactone & $\mathrm{H}$ & $705-86-2$ & 98 \\
\hline 9 & $( \pm)$-gamma-Decalactone & $\mathrm{H}$ & $706-14-9$ & 97 \\
\hline 9 & $( \pm)$-gamma-Hexalactone & $\mathrm{H}$ & $695-06-7$ & 98 \\
\hline *9 & $( \pm)$-gamma-Nonanlactone & $\mathrm{H}$ & $104-61-0$ & 97 \\
\hline 9 & $( \pm)$-gamma-Octalactone & $\mathrm{H}$ & $104-50-7$ & 97 \\
\hline 9 & $( \pm)$-gamma-Undecalactone & $\mathrm{H}$ & $104-67-6$ & 99 \\
\hline 10 & $( \pm$ )-Ethyl 3-hydroxybutyrate & $\mathrm{H}$ & $5405-41-4$ & 97 \\
\hline$* 10$ & (Z)-3-Hexenyl butyrate & $\mathrm{H}$ & $16491-36-4$ & 98 \\
\hline$* 10$ & (Z)-3-Hexenyl isobutyrate & $\mathrm{H}$ & $41519-23-7$ & 98 \\
\hline$* 10$ & (Z)-3-Hexenyl tiglate & $\mathrm{H}$ & $67883-79-8$ & 97 \\
\hline *11 & Butyl butyrate & $\mathrm{H}$ & $109-21-7$ & 98 \\
\hline$* 11$ & Ethyl butyrate & $\mathrm{H}$ & $105-54-4$ & 99 \\
\hline$* 11$ & Ethyl hexanoate & $\mathrm{H}$ & $123-66-0$ & 99 \\
\hline 11 & Ethyl propionate & $\mathrm{H}$ & $105-37-3$ & 99 \\
\hline *11 & Hexyl butyrate & $\mathrm{H}$ & $2639-63-6$ & 98 \\
\hline 11 & Methyl butyrate & $\mathrm{H}$ & $623-42-7$ & 99 \\
\hline *11 & Methyl hexanoate & $\mathrm{H}$ & $106-70-7$ & 99 \\
\hline *11 & Methyl octanoate & $\mathrm{H}$ & $111-11-5$ & 99 \\
\hline 11 & Methyl propionate & $\mathrm{H}$ & $554-12-1$ & 99 \\
\hline *11 & Propyl butyrate & $\mathrm{H}$ & $105-66-8$ & 99 \\
\hline 12 & Butyl isobutyrate & $\mathrm{H}$ & $97-87-0$ & 97 \\
\hline 12 & Hexyl hexanoate & $\mathrm{H}$ & $6378-65-0$ & 97 \\
\hline$* 12$ & Isoamyl acetate & $\mathrm{H}$ & $123-92-2$ & 98 \\
\hline *12 & Isoamyl butyrate & $\mathrm{H}$ & $106-27-4$ & 98 \\
\hline 12 & Isobutyl acetate & $\mathrm{H}$ & $110-19-0$ & 99,8 \\
\hline *12 & Isobutyl isobutyrate & $\mathrm{H}$ & $97-85-8$ & 99 \\
\hline 12 & Isopentyl isobutyrate & $\mathrm{H}$ & $2050-01-3$ & 98 \\
\hline *12 & Isopropyl acetate & $\mathrm{H}$ & $108-21-4$ & 99,8 \\
\hline 13 & Acetic acid & $\mathrm{P}$ & $64-19-7$ & 99 \\
\hline 13 & Acetone & $\mathrm{P}$ & $67-64-1$ & 99,9 \\
\hline 13 & Ethanol & $\mathrm{P}$ & $64-17-5$ & 99 \\
\hline$* 13$ & Ethyl acetate & $\mathrm{P}$ & $141-78-6$ & 99,5 \\
\hline 13 & Propionic acid & $\mathrm{P}$ & 79-09-4 & 99,5 \\
\hline
\end{tabular}

*, compound active in single sensillum recordings

\#, screening blend

$\mathrm{S}$, solvent used (A, acetone, $\mathrm{H}$, hexane, $\mathrm{P}$, paraffin oil)

CAS, Chemical Abstracts Service number

$\%$, minimum purity in percent

through a hole in the glass tube, and blowing an air puff of $2.5 \mathrm{ml}$ during $0.5 \mathrm{sec}$ through the pipette into the air stream, using a stimulus controller (Syntech SFC-1/b). Control stimuli were delivered first, followed by screening stimuli containing multiple compounds (screening blends listed in Table 1). For all screening stimuli that elicited a positive response of approximately $\geq 40 \mathrm{~Hz}$, the pipettes loaded with all compounds in the blend(s) were brought from the 
freezer and tested individually after thawing at room temperature for $5 \mathrm{~min}$.

The net response to a stimulus was obtained by counting action potentials (spikes) during $0.5 \mathrm{sec}$ starting from the time after the stimulation period at which the earliest response for the neuron was found, and deducting the number of action potentials during $0.5 \mathrm{sec}$ immediately prior to the response. Each neuron was also subjected to blank stimuli (i.e., only solvent), and the net response to the blank was deducted from the response to the test compounds. The resulting value was doubled to obtain a value corresponding to spikes/sec $(\mathrm{Hz})$. The time between the start of the stimulation period and the onset of a response, i.e., increased number of action potentials, sometimes varied between different recording sessions, due to slight variations in the air flow. For each neuron, counting of action potentials was started from the time at which the earliest response in that neuron occurred.

Field Experiments Related to GC-EAD Field experiments with the sorghum and abutilon compounds were carried out at Rasa, Ethiopia (see above). A complete randomized block design with $N=10$ was used. The distance between traps was $10 \mathrm{~m}$, and blocks were separated by at least $50 \mathrm{~m}$. Dispensers were placed in cardboard holders $(78 \times 37 \mathrm{~mm}$, Silvandersson AB, Knäred, Sweden) fitted into a slot in the vanes of Japanese beetle traps (Trécé, Palo Alto, CA, USA), which were suspended approximately $3 \mathrm{~m}$ above ground from wooden poles. The traps were emptied daily, and lures were replaced in the morning before the onset of activity for adult $P$. interrupta. Unbaited traps were used as a negative control.

Experiments were performed during two periods: July 11-16 and October 7-13, 2006. The latter tests were done during the cropping season, when the sorghum had seeds in the milky stage. The July experiments were carried out in a grazing area characterized by scattered Acacia trees. In October, traps were placed along the borders of five sorghum fields located approximately $500 \mathrm{~m}$ from the July test sites. Compounds were applied to dental cotton rolls (No. 3, Q-dent, Germany). The individual sorghum compounds, (Z)-3-hexen-1-ol, tridecane, 1-octen-3-ol, and 1-octanol, were applied at a dose of $100 \mathrm{mg}$ each. In addition to the sorghum compounds, eugenol and methyl salicylate also were tested. Two of the sorghum-related blends were tested both in July and in October: a blend of the four sorghum compounds with the same total dose $(100 \mathrm{mg})$ as for the individual compounds and in a ratio mimicking what was found in the sorghum headspace, i.e., $10 \mathrm{mg}(Z)-3$-hexen-1-ol+30 mg tridecane +30 mg 1-octen-3-ol+30 mg 1-octanol, and the same sorghum blend with the addition of $30 \mathrm{mg}$ methyl salicylate. In addition to these, three more blends were tested in October: the sorghum blend with the addition of $30 \mathrm{mg}$ eugenol, the sorghum blend with the addition of $30 \mathrm{mg}$ eugenol and $30 \mathrm{mg}$ methyl salicylate, and a blend of $50 \mathrm{mg}$ eugenol and $50 \mathrm{mg}$ methyl salicylate.

The individual abutilon compounds were also tested at a dose of $100 \mathrm{mg}$ : (Z)-3-hexen-1-ol (the same traps as in the sorghum experiment), tetradecane, methyl anthranilate, and methyl salicylate. Methyl anthranilate was tested only individually in October. An abutilon blend at a total dose of $100 \mathrm{mg}$ and with ratios mimicking the headspace collections was also tested as follows: $20 \mathrm{mg}(Z)-3$-hexen1-ol+20 mg tetradecane $+5 \mathrm{mg}$ methyl anthranilate $+55 \mathrm{mg}$ methyl salicylate. In addition, a blend without methyl salicylate was tested. Furthermore, in October, a blend consisting of the abutilon blend with the addition of $30 \mathrm{mg}$ eugenol was added to the experiment.

Field Experiments Related to SSR The materials and methods used in SSR-related field experiments were the same as those used for field experiments related to GC-EAD, except $N=5$ and treatments were moved one step within blocks each day to minimize any impact of possible position effects. Some previously untested compounds also were applied to new dispenser types (see below).

Six novel compounds selected by SSR were tested on 4-9 July 2008 on unused farmland with sparse vegetation near the village of Embuay Bad in Ethiopia $\left(09^{\circ} 48^{\prime} \mathrm{N}, 40^{\circ} 00^{\prime} \mathrm{E}\right)$, $1206 \mathrm{~m}$ above sea level, $265 \mathrm{~km}$ northeast of Addis Ababa, Ethiopia. Five of the novel compounds tested (anethole, benzaldehyde, racemic 2,3-butanediol, isoamyl alcohol, and methyl octanoate) were selected on the basis that they elicited strong SSR response in separate ORN classes that did not respond to compounds previously tested in the field. For comparison, we also included eugenol and methyl salicylate. Methyl benzoate was tested for reasons different from the other compounds - it was included since it activated the same ORN type as methyl salicylate, which previously had been shown to be highly attractive. Olfactory receptor neurons responding to eugenol did not respond to other compounds included in the screening process. Practical limitations forced us to forego testing of some compounds as it was not possible to acquire necessary quantities in suitable purity, and other compounds were not included since they are more commonly associated with foliage than fruit or flowers.

A dose of $100 \mathrm{mg}$ of pure compound (for purity and CAS number, see Table 1) was loaded onto a dispenser that was matched to the volatility (as indicated by boiling point) of the compound. This rough estimation was used to obtain comparable evaporation rates. Cotton rolls (no. 2 dental cotton roll, Demedis GmbH, Langen, Germany) were used as dispensers for anethole, eugenol, methyl benzoate, methyl octanoate, and methyl salicylate. For dispensing benzaldehyde and 2,3-butanediol, cotton rolls were pushed into $4 \mathrm{ml}$ 
vials $(45 \times 14.7 \mathrm{~mm}$, clear, Skandinaviska GeneTec AB, Västra Frölunda, Sweden) until the cotton was level with the rim of the opening of the vial. Compound was applied to the cotton roll after it had been placed in the vial. For isoamyl alcohol, a dispenser was made where a cotton roll was put inside a vial closed with a cap (black, closed top, $13 \mathrm{~mm}$, Skandinaviska GeneTec AB). A hole of approximately $2 \mathrm{~mm}$ diam was made in the cap. The cotton roll was placed so that it was in direct contact with the cap when the cap was screwed tight to the vial. The chemical was not applied to the cotton roll directly beneath the hole in the cap, but instead towards the edge of the vial, before screwing on the cap.

Statistical Analysis For field experiments, data for total catch of $P$. interrupta (cumulative over the field testing period) per trap was square root-transformed $(\sqrt{ }(\times+1))$. Data was analyzed with a General Linear Model (GLM), with treatment (type of lure) as a fixed effect, and block as a random effect (Minitab 14 for Windows). Significant GLMs were followed by Tukey's b post hoc test. The significance level used in all tests was $\alpha=0.05$. Trap catch data is presented in graphs as untransformed means with error bars denoting standard error of the mean.

\section{RESULTS}

GC-EAD Analyses and Identification of Host Plant Volatiles Several compounds in both the abutilon (Fig. 1a) and the sorghum (Fig. 1b) headspace collections elicited consistent responses in $P$. interrupta antennae. The EADactive compounds collected from abutilon headspace extracts were identified as (Z)-3-hexen-1-ol, tetradecane, methyl salicylate, and methyl anthranilate (Fig. 1a), and in sorghum as tridecane, (Z)-3-hexen-1-ol, 1-octen-3-ol, and 1-octanol (Fig. 1b). Similar antennal responses were recorded from antennae of females (not shown). In abutilon headspace extracts, methyl salicylate was a major constituent, making up approximately $14.4 \%$ of the extract. In sorghum extract, however, it was present at low concentrations, and did not elicit any antennal responses. Despite a low concentration of methyl anthranilate in the abutilon extract, this compound elicited a strong antennal response.

Field Experiments Related to GC-EAD During July and October, there were no significant differences in trap catches between the sorghum blend, which caught an average of 12 beetles per trap over the experimental period in July and 11 beetles in October (blend 8, Fig. 2), and the individual sorghum compounds. In July, traps baited with methyl salicylate caught significantly more beetles (21 beetles/trap) than traps baited with tridecane or (Z)-3-hexen-1-ol. Eugenol baited traps caught significantly more beetles (40 beetles/ trap) than all other treatments, except the sorghum blend with the addition of methyl salicylate ( 40 beetles/trap, blend 9, Fig. 2a). In October, the sorghum blend with eugenol ( 82 beetles/trap, blend 10) and the sorghum blend with eugenol and methyl salicylate (70 beetles/trap) attracted by far the highest numbers of beetles, followed by the sorghum
Fig. 1 Simultaneous response of flame ionization detector (FID) and male Pachnoda interrupta antennae (EAD) to volatile compounds collected from a abutilon and $\mathbf{b}$ sorghum. The upper traces in each figure represent the signal from the FID and the lower traces represent the signal from the EAD. The compounds collected from abutilon headspace extracts were identified as $(Z)-3$ hexen-1-ol (1), tetradecane (2), methyl salicylate (3), and methyl anthranilate (4), and in sorghum tridecane (5), (Z)-3-hexen-1-ol (1), 1-octen-3-ol (6), and 1-octanol (7)
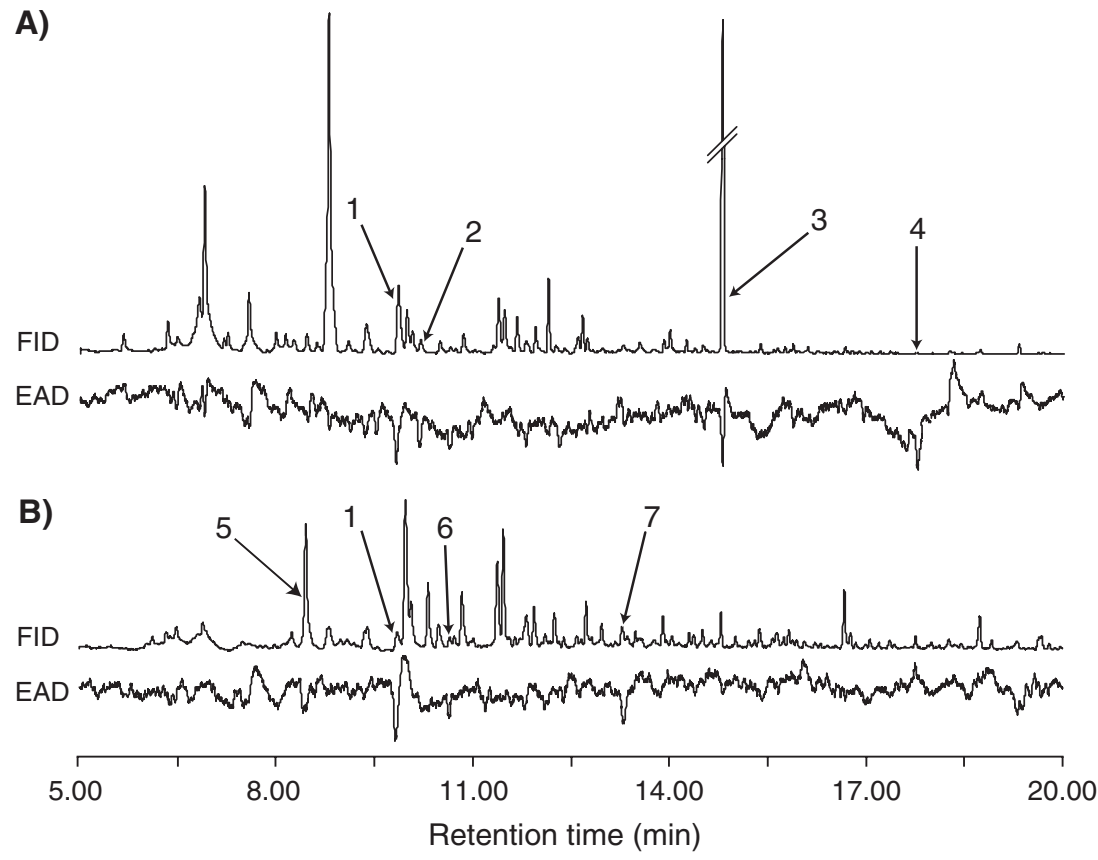
Fig. 2 Number of Pachnoda interrupta captured in traps baited with synthetic sorghum compounds in a July, 2006 and b October, 2006. Unbaited traps caught no insects and were not included in the comparison. GLM: July, $(N=10, F=78.1$, $d f=7,63, P<0.001)$; October, $(N=10, F=114.1, d f=10,90$, $P<0.001)$. Error bars show the standard error of the mean. Subgroups denoted by different letters are significantly different at $\alpha=0.05(N=10$, Tukey's $b)$. NT indicates that the treatment was not tested
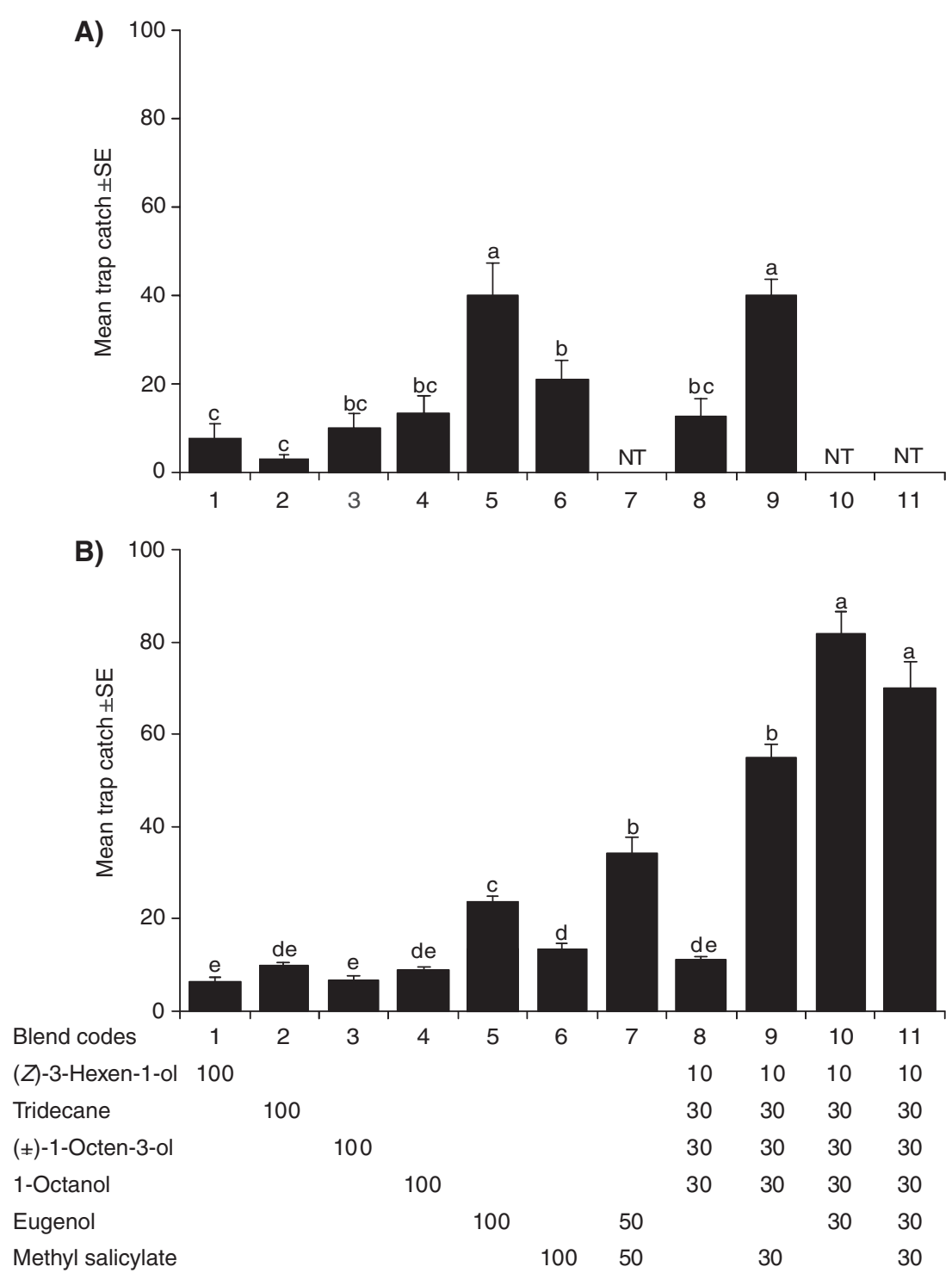

blend with methyl salicylate, the two-component eugenolmethyl salicylate blend, and eugenol alone. In both July and October, the four-component abutilon blend caught significantly more beetles ( 22 beetles/trap in July and 17 in October, blend 7, Fig. 3) than traps baited with the single compounds (Z)-3-hexen-1-ol and tetradecane. While there were no significant differences in trap catches between traps baited with the abutilon blend and the blend without methyl salicylate ( 15 beetles/trap) in July, the complete blend caught more beetles in October. In both seasons, there were no significant differences in trap catch between the abutilon blend and methyl salicylate presented as a single compound or eugenol as a single compound. When methyl anthranilate was added as a single compound in October, it was as attractive as the abutilon blend and eugenol and methyl salicylate ( 20 beetles/trap, Fig. 3b). The other treatment that was added, the four-component abutilon blend combined with eugenol, was equally attractive (42 beetles/trap, blend code 9 , Fig. 3b) as the binary mixture of methyl salicylate and eugenol (37 beetles/trap), and more attractive than any other treatment. During both seasons, all treatments caught significantly more beetles than the unbaited control traps. Male and female beetles followed the same pattern of attraction, with no clear differences between the sexes in which baits were most attractive (data not shown).

Single Sensillum Recordings The antennal morphology of $P$. interrupta is similar to that of the closely related scarab $P$. marginata, as described by Stensmyr et al. (2001). P. interrupta has a typical scarab antenna, where sensilla are present on the inner surfaces of the three lamellae at the tip of the antenna. Most sensilla are of the placodea morphological type, with a small minority of smooth peg and coeloconic sensilla. Our SSR recordings 
Fig. 3 Number of Pachnoda interrupta captured in traps baited with synthetic abutilon compounds in a July, 2006 and b October, 2006. Unbaited traps caught no insects and were not included in the comparison. GLM: July 2006, $(N=10$, $F=12.7, d f=5,45, P<0.001)$; October 2006, $(N=10, F=42.1$, $d f=8,72, P<0.001)$. Error bars show the standard error of the mean. Subgroups denoted by different letters are significantly different at $\alpha=0.05 \quad(N=10$,

Tukey's $b$ ). NT indicates that the treatment was not tested
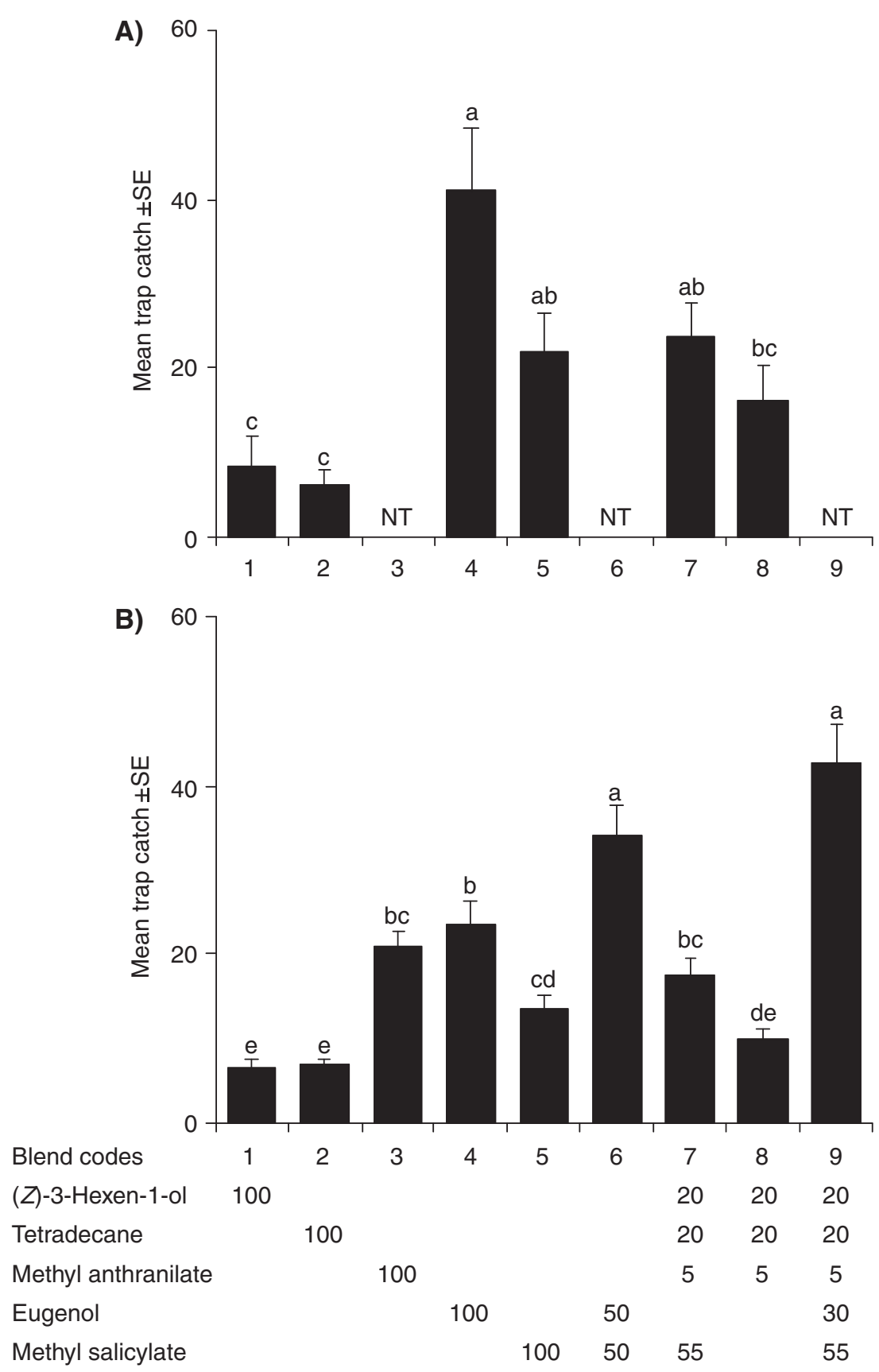

stem from sensilla placodea, as we only managed to get intermittent contacts with ORNs of the other morphological types.

Contacted sensilla typically contained two ORNs, which in most cases could be separated by differences in spike amplitude (Fig. 4). In sensilla containing two neurons, both neurons sometimes fired simultaneously, resulting in double spikes with amplitudes greater than that of either neuron by itself. When subjected to synthetic stimuli, ORNs usually responded strongly with a train of action potentials (spikes) to a few compounds. Recordings were obtained from a total of 156 sensilla in males and females. Data for the sexes were pooled, as no types of ORNs were numerous enough for a meaningful comparison between the sexes. Out of the 156 sensilla, 50 sensilla contained no ORNs responding to the stimulus spectrum tested. ORN response to stimulation with control stimuli (blank) normally was below $10 \mathrm{~Hz}$ (data not shown), but 3 ORNs gave a blank response of $50 \mathrm{~Hz}$ or above and were excluded from analysis, since we deemed that there was a risk that the cells had either been injured and were not responding properly, or that some contamination had been present in the odor stimulation system. We also excluded 8 ORNs for which no compound elicited a net response of 
Fig. 4 The two ORNs present in this sensillum are distinguished by the amplitudes of their action potentials. The ORN responding to linalool oxide (denoted "A") has a higher amplitude than the ORN responding to methyl salicylate (B). There are also double spikes, where both neurons fire simultaneously (D), that have a greater amplitude than either neuron by itself

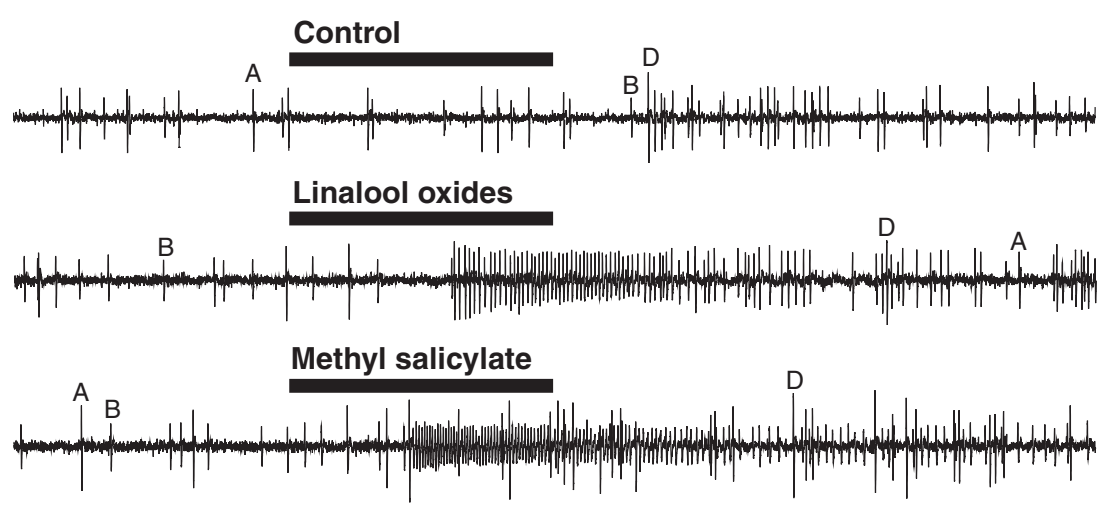

Stimulation ( 0.5 seconds)
$40 \mathrm{~Hz}$ or above, as these weak responses were unlikely to indicate key stimuli suited for evaluation in field trials. The remaining 97 neurons responded with a net response of $40 \mathrm{~Hz}$ or above to at least one stimulus. Of the 82 test compounds, 57 elicited spike responses over $80 \mathrm{~Hz}$ at least once (Table 1). Not all responses could be assigned to a specific class, but 94 responding ORNs could be grouped tentatively into 26 classes (Table 2). In most cases, ORNs responded to a single compound or a group of functionally or structurally similar compounds with one eliciting a stronger response than the rest. For some neurons, several compounds elicited strong responses, with no clear ranking between the 2-3 best compounds. A few ORNs had wide response spectra, with 5-10 compounds eliciting strong responses. For ORN classes, the average response to ligands is shown down to $40 \mathrm{~Hz}$ (Table 2).

Several of the ORN classes responded to stimulation with compounds that commonly occur in the volatile profiles of fruit and flowers (Table 2). There also were classes that responded to stimulation with compounds associated with foliage, i.e., green leaf volatiles (GLVs). No ORN response was found to ethanol, acetone, acetic acid, or propionic acid, and there was only one response to ethyl acetate. However, ORNs responded to isovaleric acid, acetoin, racemic 2,3-butanediol, 4-ethylphenol, and 4-methylphenol.

Field Experiments Related to SSR Traps baited with racemic 2,3-butanediol caught significantly more beetles over the experimental period than traps baited with other compounds (an average of 205 beetles/trap, Fig. 5; $F=80.56, P<0.001$ ), catching three times more beetles than the second best bait, eugenol (which caught 69 beetles/trap), and six times more than the third best, methyl salicylate (36 beetles/trap). Apart from 2,3-butanediol, traps baited with previously untested compounds did not catch significantly more $P$. interrupta than the unbaited control traps. Males and females follow the same pattern of attraction; there were no clear differences between the sexes for which baits were most attractive (data not shown).

\section{Discussion}

Some insect species require specific blends of several compounds to be attracted to their host (Bruce et al., 2005), e.g., the apple maggot fly, Rhagoletis pomonella (Linn et al., 2005), the grapevine moth, Lobesia botrana (Tasin et al. 2006, 2007), and the fruit fly, Drosophila melanogaster (Zhu et al. 2003; Ruebenbauer et al. 2008). However, for many fruit and flower visiting scarabs, individual compounds constitute efficient attractants (Donaldson et al. 1990). Relying on key compounds rather than specific blends could be an efficient general host detection strategy for a polyphagous herbivore such as $P$. interrupta. Such a strategy could be enhanced by the presence of reliable signals from plants that attract animals for pollination or fruit (seed) dispersal. Our results from field experiments with blends that mimic the hosts abutilon and sorghum indicated that $P$. interrupta is attracted to a few key components in the volatile profiles of these plants, rather than ratio-specific blends (Fig. 2 and 3), and thus we focused our search for attractants on single compounds. As we also noted that the most attractive compounds were associated with fruits and flowers (e.g., eugenol and methyl salicylate), rather than foliage [e.g., (Z)-3-hexen-1-ol], we primarily tested floral- and fruit-related kairomones in the single sensillum screening. Among the kairomones selected for screening, many have been found in several hosts of P. interrupta, e.g., banana (Macku and Jennings 1987; Ibáñes et al. 1998; Boudhrioua et al. 2003) guava (Carasek and Pawliszyn 2006), mango (Clara et al. 2007; Pandit et al. 2009), and various flowers (Knudsen et al., 2006). We also included fermentation volatiles (Chatonnet et al. 1992; Fischer et al. 2000; Xiao and Ping 2007), since the sorghum 
Table 2 Olfactory receptor neuron classes in the sorghum chafer, Pachnoda interrupta

\begin{tabular}{|c|c|}
\hline ORN class 1: 2-Hexen-1-ol & $n=2$ \\
\hline $\begin{array}{c}\text { (E)-2-Hexen-1-ol [104] } \\
\text { 1-Hexanol [90] } \\
(Z)-3 \text {-Hexen-1-ol [88] } \\
(E)-3 \text {-Hexen-1-ol [74] } \\
(Z) \text {-3-Hexenyl acetate [47] }\end{array}$ & \\
\hline ORN class 2: 3-Hexen-1-ol & $n=6$ \\
\hline $\begin{array}{c}\text { (E)-3-Hexen-1-ol [114] } \\
\text { (Z)-3-Hexen-1-ol [113] } \\
(\text { E)-2-Hexen-1-ol [59] } \\
\text { (Z)-3-Hexenyl acetate [44] }\end{array}$ & \\
\hline
\end{tabular}

\begin{tabular}{|c|c|}
\hline ORN class 3: Nonanal & $n=7$ \\
\hline \multicolumn{2}{|l|}{ Nonanal [108] } \\
\hline ORN class 4: Isovaleric acid & $n=6$ \\
\hline Isovaleric acid [85] & \\
\hline ORN class 5: $\mathrm{N}$-Caproic acid & $n=1$ \\
\hline N-Caproic acid [85] & \\
\hline
\end{tabular}

\begin{tabular}{|cc|}
\hline ORN class 6: Butyric acid & $\mathrm{n}=1$ \\
\hline Butyric acid [82] \\
Valeric acid [60]
\end{tabular}

\begin{tabular}{|cc|}
\hline ORN class 7: 4-Methylphenol & $n=5$ \\
\hline 4-Methylphenol [84] \\
\hline
\end{tabular}

\begin{tabular}{|c|}
\hline ORN class 8: Benzaldehyde \\
\hline Benzaldehyde [72] \\
\hline
\end{tabular}

\begin{tabular}{|cc|}
\hline ORN class 9: Benzylalcohol & $\mathrm{n}=2$ \\
\hline Benzylalcohol [78] & \\
4-Ethylphenol [46] & \\
4-Methylphenol [46] & \\
\hline
\end{tabular}

\begin{tabular}{|cc|}
\hline ORN class 10: Phenylacetaldehyde & $\mathrm{n}=2$ \\
\hline Phenylacetaldehyde [72] & \\
Phenylacetonitrile [64] & \\
2-Phenylethanol [46] & \\
\hline
\end{tabular}

\begin{tabular}{|c|c|}
\hline ORN class 11: Anethole & $n=4$ \\
\hline $\begin{aligned} & \text { Anethole [110] } \\
&\end{aligned}$ & \\
\hline \begin{tabular}{|l} 
ORN class 12: racemic 2,3-Butanediol \\
\end{tabular} & $n=3$ \\
\hline
\end{tabular}

\begin{tabular}{|c|}
\hline ORN class 13: Eugenol \\
\hline Eugenol [123] \\
\hline
\end{tabular}

\begin{tabular}{|cc|}
\hline ORN class 14: Methyl salicylate & $\mathrm{n}=12$ \\
\hline $\begin{array}{c}\text { Methyl salicylate [110] } \\
\text { Methyl benzoate [64] }\end{array}$ & \\
\hline
\end{tabular}

\begin{tabular}{|cc|}
\hline ORN class 15: Linalool oxides & $\mathrm{n}=7$ \\
\hline $\begin{array}{c}\text { Linalool oxides [86] } \\
\text { Linalool [70] }\end{array}$ \\
\hline
\end{tabular}

\begin{tabular}{|cc|}
\hline ORN class 16: Geraniol & $\mathrm{n}=1$ \\
\hline Geraniol [107] & \\
(-)-trans-Citronellol [89] & \\
(E)-2-Hexenyl acetate [85] & \\
(Z)-3-Hexenyl acetate [83] & \\
Methyl octanoate [82] & \\
2-Phenethyl propionate [77] & \\
(Z)-3-Hexenyl isobutyrate [75] & \\
\hline
\end{tabular}

\begin{tabular}{|c|c|}
\hline ORN class 17: Geranyl acetate & $\mathrm{n}=2$ \\
\hline \multicolumn{2}{|l|}{ Geranyl acetate [88] } \\
\hline ORN class 18: ( \pm )-Ethyl 3-hydroxybutyrate & $n=1$ \\
\hline $\begin{array}{c}( \pm) \text {-Ethyl 3-hydroxybutyrate [49] } \\
(-)-\text { trans-Citronellol [43] }\end{array}$ & \\
\hline ORN class 19: Methyl anthranilate & $\mathrm{n}=1$ \\
\hline Methyl anthranilate [50] & \\
\hline ORN class 20: Methyl cinnamate & $n=1$ \\
\hline Methyl cinnamate [59] & \\
\hline ORN class 21: ( \pm )-beta-Caryophyllene & $\mathrm{n}=6$ \\
\hline$( \pm)$-beta-Caryophyllene [82] & \\
\hline ORN class 22: Butyl butyrate & $\mathrm{n}=6$ \\
\hline $\begin{array}{c}\text { Butyl butyrate [83] } \\
( \pm)-3-O c t a n o l ~[81] \\
\text { Butyl isobutyrate [80] } \\
\text { Methyl hexanoate [77] } \\
\text { Isoamyl butanoate [69] } \\
\text { Isoamyl acetate [65] } \\
\text { 6-Methyl-5-hepten-2-one [65] } \\
\text { Propyl butyrate [60] } \\
\text { Ethyl hexanoate [57] } \\
( \pm)-1-O c t e n-3-0 l[49]\end{array}$ & \\
\hline
\end{tabular}

\begin{tabular}{|c|c|}
\hline ORN class 23: 6-Methyl-5-hepten-2-one & $n=1$ \\
\hline 6-Methyl-5-hepten-2-one [102] & \\
\hline ORN class 24: Methyl octanoate & $\mathrm{n}=4$ \\
\hline $\begin{array}{l}\text { Methyl octanoate [101] } \\
\text { Hexyl acetate [66] } \\
\text { Methyl hexanoate [56] }\end{array}$ & \\
\hline
\end{tabular}

\begin{tabular}{|c|}
\hline ORN class 25: Isoamyl alcohol \\
\hline Isoamyl alcohol [127] \\
(Z)-3-Hexenyl isobutyrate [93] \\
Methyl octanoate [83] \\
Butyl butyrate [67] \\
Propyl butyrate [65] \\
Linalool oxides [63] \\
Ethyl hexanoate [61] \\
(Z)-3-Hexenyl butyrate [61] \\
Linalool [59] \\
Methyl benzoate [57] \\
Methyl hexanoate [49] \\
2-Phenyl ethanol [49] \\
Hexyl butyrate [47] \\
( \pm -Acetoin [47] \\
Phenylacetonitrile [45] \\
Ethyl butyrate [45] \\
\hline
\end{tabular}

\begin{tabular}{|c|}
\hline ORN class 26: Unsaturated esters \\
\hline (Z)-3-Hexenyl isobutyrate [82] \\
(Z)-3-Hexenyl tiglate [65] \\
(Z)-3-Hexenyl butyrate [57] \\
Geraniol [51] \\
2-Phenylethanol [50] \\
(Z)-3-Hexenyl acetate [42] \\
\hline
\end{tabular}

Average net response in $\mathrm{Hz}$ to key ligands shown in [brackets]; for $n=1$, net response shown (all responses above $40 \mathrm{~Hz}$ are included) ORNs grouped according to stimuli that excite their strongest responses " $n$ " indicates number of ORNs that belong in each class 


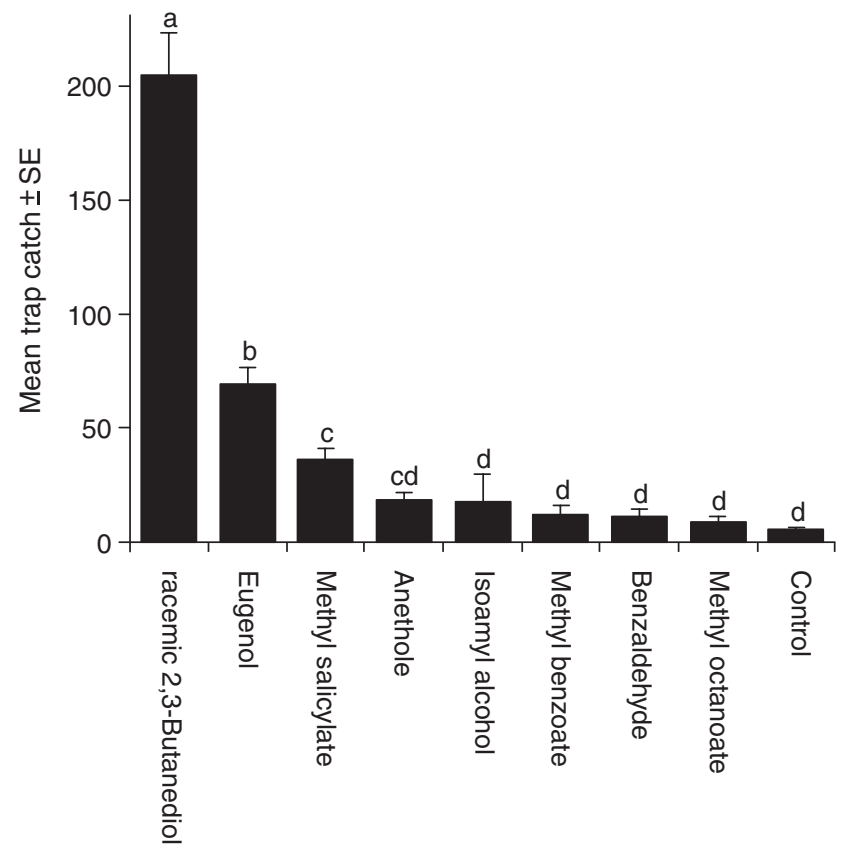

Fig. 5 Average trap catch of Pachnoda interrupta in July 2008. The type of bait had a significant effect on catch (GLM, N=10, $F=80.56$, $d f=8,72, P<0.001)$. Error bars show the standard error of the mean. Subgroups denoted by different letters are significantly different at $\alpha=0.05(N=10$, Tukey's $b)$

chafer has been reported to be attracted to residue from the fermentation of tella beer. The use of single sensillum recordings (SSR) for screening of potential kairomones enabled us to select compounds for field testing that activate separate olfactory receptor neuron (ORN) classes. Regardless of how information from the olfactory system is interpreted at higher levels of the nervous system, the activation of additional components of the ORN array should increase the likelihood of releasing a behavior, compared to redundant activation of the same ORN classes with several different compounds. Behavioral redundancy between compounds that activate the same ORN class has been observed in the bark beetle Ips typographus, where compounds detected by the same ORN do not cause any synergistic repellent effects when combined in field trapping experiments (Andersson et al. 2009). Broad response spectra for ORNs could be an efficient solution for detecting several compounds that relay essentially the same information (Baker et al. 1998; Cossé et al. 1998; Wojtasek et al. 1998; Larsson et al. 2002).

The best field attractants in our study (Fig. 2, 3 and 5) and in a previous study (Wolde-Hawariat et al. 2007) were all detected by single ORN classes - no response to these ligands were found in other ORN classes (Table 2). Thus, activation of a single ORN class seems to be sufficient for the release of attraction behavior. Results from I. typographus also indicate that several compounds may cause sufficient activation of a single ORN class to release behavior (Andersson et al. 2009). Methyl benzoate thus was included in the field experiment as it was a secondary ligand of methyl salicylate ORNs (Table 2). Methyl salicylate was highly attractive to $P$. interrupta in the field (Wolde-Hawariat et al. 2007), and to P. marginata in a two-choice bioassay (Larsson et al. 2003), even though it was detected by one of the least commonly found ORNs in P. marginata (Stensmyr et al. 2001). Methyl salicylate is the primary odorant for a particular ORN in the moth Mamestra brassicae, and as in $P$. interrupta, this neuron also has a weaker secondary response to methyl benzoate (Ulland et al. 2008). In $M$. brassicae, egg-laying was inhibited by the presence of methyl salicylate on dispensers near the host plant (cabbage) while methyl benzoate was not tested (ibid.). In our field experiments, catches of $P$. interrupta in traps baited with methyl benzoate were not significantly higher than that of control traps (Fig. 5). Testing of other compounds that elicit secondary responses in ORN classes that respond to attractive compounds could shed light on their role in insect behavior. Despite the fact that $P$. interrupta is attracted strongly to fermentation products such as tella beer residue (Ministry of Agriculture and Ethiopian Agricultural Research Organization 1999), ORNs that respond to primary fermentation products such as ethanol, acetic acid, propionic acid, or acetone, appear to be absent or rare on the P. interrupta antenna. Some of these compounds are attractive to other insects that feed on fermenting substrates (e.g., fruit), such as D. melanogaster, which are attracted to acetic acid, acetone, and ethanol in lab trapping bioassays (Zhu et al. 2003; Ruebenbauer et al. 2008). We did, however, find ORNs in $P$. interrupta that responded to other substances related to fermentation and microbial degradation, such as racemic 2,3butanediol, acetoin, 4-ethylphenol, 4-methylphenol, and ethyl acetate (one neuron). The ORN class in P. interrupta responding to 2,3-butanediol also responded to acetoin. In the closely related $P$. marginata, acetoin was significantly more attractive than a blank control in a two-choice bioassay, while racemic 2,3-butanediol was not (Larsson et al. 2003). This is interesting as both ligands are detected by the same ORN, and none of the other ORN classes found in the study respond to either compound (Stensmyr et al. 2001). Acetoin and 2,3-butanediol are active in other beetle species as well, where certain isomers or mixtures of isomers are often needed to elicit activity. Meso-2,3-butanediol, $(2 R, 3 R)-2,3-$ butanediol, and $(R)$-acetoin are emitted by female Rhizotrogus majalis and detected only by male antennae in EAD (Nojima et al. 2003). Male Scapanes australis emit acetoin, 2-butanol, and 2,3-butanediol, with the first two being necessary and sufficient to attract both sexes in field trapping experiments (Rochat et al. 2002). (R)-acetoin has been identified as a female-emitted sex pheromone in the summer chafer, Amphimallon solstitiale (Tolasch et al. 2003). In the palm 
weevil, Rhynchophorus palmarum, acetoin is a synergist to male-emitted volatile aggregation pheromones. The addition of either acetoin or plant matter is necessary to elicit high levels of attraction; the pheromone alone does not suffice (Said et al. 2005).

In the SSR screening, we found ORNs that responded to five of the seven compounds identified as active by GC-EAD (methyl anthranilate, methyl salicylate, (Z)-3-hexen-1-ol, 1-octanol, and 1-octen-3-ol), but we did not find any responses to tetradecane or tridecane (Table 1, 2). It is possible that tetradecane and tridecane are detected by one or several rare ORN types, or by ORNs present in smooth peg sensilla or sensilla coeloconica, to which we had only intermittent contacts. Discrepancies between electroantennographic and single sensillum methods have been observed in previous studies (Blight et al. 1995; Barata et al. 2002; Wibe 2004). Wibe (2004) compared GC-EAD and GC-SSR as tools for identification of active compounds for the pine weevil, Hylobius abietis, in aerations of sawdust from Norway spruce (Picea abies), and found that GC-SSR led to the identification of a higher number of active compounds than GC-EAD.

Apart from racemic 2,3-butanediol, the most attractive compounds in the field were eugenol, methyl anthranilate, and methyl salicylate (Fig. 2, 3, and 5). These compounds are common floral volatiles (Knudsen et al. 2006), with eugenol and methyl salicylate often found in aerations of Acacia spp. flowers (Lamarque et al. 1998). Methyl salicylate also is found in leaf odors (Buttery et al. 1982; Loughrin et al. 1997; Shulaev et al. 1997), and is a common defensive compound in higher plants in response to herbivory (Kessler and Baldwin 2001). In field experiments, volatiles emitted from surrounding vegetation thus may include some of the compounds tested, or similar compounds, which could affect the results of field experiments. In the sites used, there is seasonal variation in vegetation and phenology. A salient example is sorghum, which has flowers and seeds in stages attractive to the beetles in October, but not in July. This also coincides with life cycle changes in the beetles, which may affect trap catch. Sorghum chafers mate and feed in July, while in October, the newly emerged adults feed only before going into aestivation until July the following year. Experiments evaluating the effects of these factors were outside the scope of our study.

By using SSR to target a large fraction of the peripheral olfactory system, we identified racemic 2,3-butanediol as an efficient field attractant, without needing to test all of the 57 compounds in our screening that elicited response (Table 1, 2). This compound could be useful in future control or monitoring, especially since it is highly attractive to both male and female P. interrupta. Future field experiments should clarify which isomers of 2,3-butanediol (or mixtures thereof) are responsible for attraction. Field tests also should include other fruit- or flower-related compounds that activate so far untested ORN classes, as well as further compounds related to microbial degradation or fermentation, and blends of the best attractants. P. interrupta may serve as a useful model for future research on host searching in polyphagous fruit- and flower-feeding insects.

Acknowledgments We thank the National Herbarium of Addis Ababa University (Science Faculty) for the identification of A. figarianum. We acknowledge the Plant Protection and Regulatory Department of Ministry of Agriculture and Rural Development of Ethiopia for providing traps for experiments. This work was financed mainly by a grant from the Swedish International Development Agency (Sida/SAREC), for which the authors are grateful. In addition, Swedish support was supplied by the IC-E ${ }^{3}$ Linnaeus program. The authors are also grateful for the complimentary financial support provided by the Ethiopian Institute of Agricultural Research, especially the secretariat for the Agricultural Research Fund.

\section{References}

ANDERsSon M. N., LARSSON M. C., and Schlyter F. 2009. Specificity and redundancy in the olfactory system of Ips typographus: Single-cell responses to ecologically relevant odours. J. Insect Physiol. 55: 556-567.

ARN H., StÄDlER E., and RAUSCHER S. 1975. The electroantennographic detector - a selective and sensitive tool in the gas chromatographic analysis of insect pheromones. Z. Naturforsch. 30: 722-725.

BAKer T. C., FADAmiro H. Y., and Cossé A. A. 1998. Moth uses fine tuning for odour resolution. Nature 393: 530.

Barata E. N., Mustaparta H., Pickett J. A., Wadhams L. J., and ARAUJO J. 2002. Encoding of host and non-host plant odours by receptor neurons in the eucalyptus woodborer, Phoracantha semipunctata (Coleoptera: Cerambycidae). J. Comp. Physiol. 188: 121-133.

Birgersson G., and BergströM G. 1989. Volatiles released from individual spruce bark beetle entrance holes: Quantitative variations during the first week of attack. J. Chem. Ecol. 15: 2465-2483.

Blight M. M., Pickett J. A., Wadhams, L. J., and Woodcock C. M. 1995. Antennal perception of oilseed rape, Brassica napus (Brassicaceae), volatiles by the cabbage seed weevil Ceutorhynchus assimilis (Coleoptera, Curculionidae). J. Chem. Ecol. 21: 1649-1664.

Boudhrioua N., Giampaoli C., and Bonazzi C. 2003. Changes in aromatic components of banana during ripening and air-drying. Lebensm. Wiss. u. Technol. 36: 633-642.

BrucE T. J. A., WadHAMS L. J., and WoodCock C. M. 2005. Insect host location: a volatile situation. Trends in Plant Sci. 10: 269 274.

Buttery R. G., Kamm J. A., and Ling L. C. 1982. Volatile components of alfalfa flowers and pods. J. Agric. Food Chem. 30: 739-742.

CARAsek E., and PAWLiszyn J. 2006. Screening of Tropical Fruit Volatile Compounds Using Solid-Phase Microextraction (SPME) Fibers and Internally Cooled SPME Fiber. J. Agric. Food Chem. 54: 8688-8696.

Chatonnet P., Dubourdieu D., Boidron J. N., and Pons M. 1992. The Origin of Ethylphenols in Wines. J. Sci. Food Agric. 60: 165-178. 
Clara E. Q., Guillermo S., and Jorge A. P. 2007. Aroma volatile constituents of Colombian varieties of mango (Mangifera indica L.). Flavour and Fragrance Journal 22: 401-406.

Clark R. O. S., and Crowe T. J. 1978. The genus Pachnoda in Ethiopia. Identification, pest status and control of the species. Institute of Agricultural Research, Addis Ababa, Ethiopia. pp. 19.

Cossé A. A., TODD J. L., and BAKER T. C. 1998. Neurons discovered in male Helicoverpa zea antennae that correlate with pheromonemediated attraction and interspecific antagonism. J. Comp. Physiol. A 182: 585-594.

Donaldson J. M. I., MCGovern T. P., and LadD T. L. J. 1990. Floral Attractants for Cetoniinae and Rutelinae (Coleoptera: Scarabaeidae). J. Econ. Entomol. 83: 1298-1305.

Fischer U., Strasser M., and GutZler K. 2000. Impact of fermentation technology on the phenolic and volatile composition of German red wines. Int. J. Food Sci. Technol. 35: 81-94.

GRUNSHAW J. P. 1992. Field Studies on the Biology and Economic Importance of Pachnoda interrupta (Coleoptera: Scarabaeidae) in Mali West Africa. Bull. Entomol. Res. 82: 19-27.

HILlbuR Y. 2001. Tracking the tiny - Identification of sex pheromone of the pea midge as prerequisite for pheromone based monitoring. PhD Dissertation. Swedish University of Agricultural Sciences, Alnarp.

HгwOT L. 2000. Historical background on the pest status and control of sorghum chafer, Pachnoda interrupta (Coleoptera: Scarabaeidae) in Ethiopia. Proceedings of the Workshop on the Development of Monitoring and Control Strategy Against Sorghum Chafer, Pachnoda interrupta (Coleoptera: Scarabaeidae) in Ethiopia, MOA, Addis Ababa, Ethiopia. 9-15.

HuBEL D. H. 1957. Tungsten microelectrode for recording from single units. Science 125: 549-550.

IBÁÑES E., LÓPEZ-SEBASTIÁN S., RAMOS E., TABERA J., and REgLERO G. 1998. Analysis of volatile fruit components by headspace solid-phase microextraction. Food Chem. 63: 281-286.

JAGO N. D. 1995. Population monitoring and crop loss assessment in integrated pest management of panicle pests of sorghum and pearl millet. pp. 103-113, in O. Youm (ed.) Panicle Insect Pests of Sorghum and Pearl Millet. ICRISAT, Niamey, Niger,

KESSLER A., and BALDWIN I. T. 2001. Defensive function of herbivore-induced plant volatile emissions in nature. Science 291: 2141-2144

KNUdSEn J. T., ERIKSSON R., Gershenzon J., and Stahl B. 2006. Diversity and distribution of floral scent. Botan. Rev. 72: 1-120.

Lamarque A. L., Maestri D. M., Zygadlo J. A., and Grosso N. R. 1998. Volatile constituents from flowers of Acacia caven (Mol.) Mol. var. caven, Acacia aroma Gill. ex Hook., Erythrina crista-galli L. and Calliandra tweedii Benth. Flavour and Fragrance Journal 13: 266-268.

Larsson M. C., Hallberg E., Kozlov M. V., Francke W., HANSSON B. S., and LOFSTEDT C. 2002. Specialized olfactory receptor neurons mediating intra- and interspecific chemical communication in leafminer moths Eriocrania spp. (Lepidoptera: Eriocraniidae). J. Exp. Biol. 205: 989-998.

LARSSON M. C., LEAL W. S., and HANSSON B. S. 2001. Olfactory receptor neurons detecting plant odours and male volatiles in Anomala cuprea beetles (Coleoptera: Scarabaeidae). J. Insect Physiol. 47: 1065-1076.

Larsson M. C., Stensmyr M. C., Bice S. B., and Hansson B. S. 2003. Attractiveness of fruit and flower odorants detected by olfactory receptor neurons in the fruit chafer Pachnoda marginata. J. Chem. Ecol. 29: 1253-1268.

LEAL W. S., MochizUKi F., WAKAMURa S., and YASUdA T. 1992. Electroantennographic detection of Anomala cuprea Hope (Coleoptera: Scarabaeidae) sex pheromone. J. Appl. Entomol. Zool. 27: 289-291.
Linn C. E., Dambroski H., Nojima S., Feder J. L., Berlocher S. H., and RoElofS W. L. 2005. Variability in response specificity of apple, hawthorn, and flowering dogwood-infesting Rhagoletis flies to host fruit volatile blends: implications for sympatric host shifts. Entomol. Exp. App. 116: 55-64.

LOUghrin J. H., Potter D. A., HAMiLton-Kemp T. R., and Byers M. E. 1997. Diurnal emission of volatile compounds by Japanese beetle damaged grape leaves. Phytochemistry 45: 919-923.

Macku, C.,, and Jennings, W., G., 1987. Production of Volatiles by Ripening Bananas. J. Agric. Food Chem. 35: 845-848.

Ministry OF AgRiculture and Ethiopian AgricUltural RESEARCH Organization. 1999. Control measures used by farmers and associated problems. Proceedings of a Workshop on the Significance, Distribution and Control of Sorghum Chafer, Pachnoda interrupta (Olivier) (Coleoptera: Scarabaeidae) in Amhara and Afar regions, Ministry of Agriculture \& Ethiopian Agricultural Research Organization, Addis Ababa, Ethiopia. 19-23.

MustaparTA H. 2002. Encoding of plant odour information in insects: Peripheral and central mechanisms. Entomol. Exp. App. 104: 1-13.

Nojima S., SaKata T., Yoshimura K., Robbins P. S., Morris B. D., and RoelofS W. L. 2003. Male-Specific EAD Active Compounds Produced by Female European Chafer Rhizotrogus majalis (Razoumowsky). J. Chem. Ecol. 29: 503-507.

Pandit S. S., Chidley H. G., Kulkarni R. S., Pujari K. H., GiRi A. P., and GUPTA V. S. 2009. Cultivar relationships in mango based on fruit volatile profiles. Food Chemistry 114: 363-372.

Potter D. A., and Held D. W. 2002. Biology and Management of the Japanese Beetle. Annu. Rev. Entomol. 47: 175-205.

RigOUT J. 1989. Beetles of the World. Sciences Nat, Venette.

Rochat D., Morin J.-P., KakUl T., Beaudoin-Ollivier L., Prior R., Renou M., Malosse I., Stathers T., Embupa S., and Laup S. 2002. Activity of Male Pheromone of Melanesian Rhinoceros Beetle Scapanes australis. J. Chem. Ecol. 28: 479-500.

Ruebenbauer A., Schlyter F., Hansson B. S., LÖFstedt C., and LARSSON M. C. 2008. Genetic variability and robustness of host odour preference in Drosophila melanogaster. Curr. Biol. 18: $1438-1443$.

Said I., Renou M., Morin J.-P., Ferreira J. M. S., and Rochat D. 2005. Interactions between Acetoin, a Plant Volatile, and Pheromone In Rhynchophorus palmarum: Behavioral and Olfactory Neuron Responses. J. Chem. Ecol. 31: 1789-1805.

Sastawa B. M., and Lale N. E. S. 2000. Efficacy of host plant resistance, sowing date modification and intercropping as methods for the control of Pachnoda interrupta (Olivier) in pearl millet in the Nigerian Sudan savanna. J. Arid Environ. 46: 249-262.

SCHMUTTERER H. 1969. Pests of Crops in Northeast Africa and Central Africa. Gustav Fischer Verlag, Stuttgart, Portland-USA.

ShUlAeV V., Silverman P., and RASKIN I. 1997. Airborne signaling by methyl salicylate in plant pathogen resistance. Nature 385 : 718-720.

Stensmyr M. C., Larsson M. C., Bice S., and Hansson B. S. 2001. Detection of fruit- and flower-emitted volatiles by olfactory receptor neurons in the polyphagous fruit chafer Pachnoda marginata (Coleoptera: Cetoniinae). J. Comp. Physiol. A 187: 509-519.

TAsin M., BÄCKMAN A.-C., Bengtsson M., IORiatti C., and WitzGaLl P. 2006. Essential host plant cues in the grapevine moth. Naturwissen. 93: 141-144.

TAsin M., BÄCKMAN A-C., Coracini M., CASAdo D., Ioriatti C., and WitzGall P. 2007. Synergism and redundancy in a plant volatile blend attracting grapevine moth females. Phytochemistry 68: 203-209. 
Tolasch T., Solter S., Toth M., Ruther J., and Francke W. 2003. (R)-Acetoin-Female Sex Pheromone of the Summer Chafer Amphimallon solstitiale (L.). J. Chem. Ecol. 29: 10451050.

Ulland S., Ian E., Mozuraitis R., Borg-Karlson A. K., Meadow R., and Mustaparta H. 2008. Methyl Salicylate, Identified as Primary Odorant of a Specific Receptor Neuron Type, Inhibits Oviposition by the Moth Mamestra Brassicae L. (Lepidoptera, Noctuidae). Chem. Senses 33: 35-46.

WIBE A. 2004. How the choice of method influence on the results in electrophysiological studies of insect olfaction. J. Insect Physiol. 50: 497-503.

WojtaseK H., HANSSON B. S., and LeAL W. S. 1998. Attracted or Repelled? - A Matter of Two Neurons, One Pheromone Binding Protein, and a Chiral Center. Biochem. Biophys. Res. Commun. 250: 217-222.

Wolde-Hawariat Y., Seyoum E., Jembere B., Negash M., Hansson B. S., and HiLLBUR Y. 2007. Behavioural and electrophysiological response of sorghum chafer Pachnoda interrupta (Coleoptera: Scarabaeidae) to plant compounds. Int. J. Trop. Insect Sci. 27: $53-61$.

Wu W. Q., Hansson B. S., and Lofstedt C. 1995. Electrophysiological and behavioural evidence for a fourth sex pheromone component in the turnip moth, Agrotis segetum. Physiological Entomology 20: 81-92.

XiAo Z., and PING X. 2007. Acetoin metabolism in bacteria. Cr. Rev. Microbiol 33: 127-140.

YitBAREK W. H., and Hiwot L. 2000. Yield loss assessment of sorghum chafer, Pachnoda interrupta (Coleoptera: Scarabaeidae) in Ethiopia. Proceedings of the Workshop on the Development of Monitoring and Control Strategy Against Sorghum Chafer, Pachnoda interrupta (Coleoptera: Scarabaeidae) in Ethiopia, MOA, Addis Ababa, Ethiopia. 40-43.

ZHU J., PARK K.-C., and BAKER T. C. 2003. Identification of odors from overripe mango that attract vinegar flies, Drosophila melanogaster. J. Chem. Ecol. 29: 899-909. 